\title{
Kinetics of Capability Aging in Ti-13Nb-13Zr Alloy
}

\author{
Myoungjae Lee ${ }^{1}$, In-Su Kim ${ }^{1,2}$, Young Hoon Moon ${ }^{1}{ }^{1}$, Hyun Sik Yoon ${ }^{3}$, Chan Hee Park ${ }^{2}$ and \\ Taekyung Lee ${ }^{1, *(D)}$ \\ 1 School of Mechanical Engineering, Pusan National University, Busan 46241, Korea; \\ leo1991@pnu.ac.kr (M.L.); sionsy@kims.re.kr (I.-S.K.); yhmoon@pusan.ac.kr (Y.H.M.) \\ 2 Advanced Metals Division, Korea Institute of Materials Science, Changwon 51508, Korea; chpark@kims.re.kr \\ 3 Department of Naval Architecture and Ocean Engineering, Pusan National University, Busan 46241, Korea; \\ lesmodel@pusan.ac.kr \\ * Correspondence: taeklee@pnu.ac.kr
}

Received: 27 July 2020; Accepted: 10 August 2020; Published: 11 August 2020

check for updates

\begin{abstract}
Metals for biomedical implant applications require a simultaneous achievement of high strength and low Young's modulus from the viewpoints of mechanical properties. The American Society for Testing and Materials (ASTM) standards suggest two types of processing methods to confer such a mechanical performance to Ti-13Nb-13Zr alloy: solution treatment (ST) and capability aging (CA). This study elucidated the kinetics of CA process in Ti-13Nb-13Zr alloy. Microstructural evolution and mechanical change were investigated depending on the CA duration from 10 min to $6 \mathrm{~h}$. The initial ST alloy possessed the full $\alpha^{\prime}$-martensitic structure, leading to a low strength, low Young's modulus, and high ductility. Increasing CA duration increased mechanical strength and Young's modulus in exchange for the reduction of ductility. Such a tendency is attributed to the decomposition of $\alpha^{\prime}$ martensite into $(\alpha+\beta)$ structure, particularly hard $\alpha$ precipitates. Mechanical compatibility (i.e., Young's modulus compensated with a mechanical strength) of Ti-13Nb-13Zr alloy rarely increased by changing CA duration, suggestive of the intrinsic limit of static heat treatment.
\end{abstract}

Keywords: titanium; Ti-13Nb-13Zr; aging; microstructure; tensile properties; Young's modulus

\section{Introduction}

Ti-6Al-4V alloy is one of the most used titanium alloys due to its good mechanical properties, lightweight characteristics, and high corrosive resistance. The alloy has been used in various industries including aerospace, automotive, and biomedical applications. For the last section, however, researchers have claimed that toxic $\mathrm{Al}$ and $\mathrm{V}$ ions are released in a human body by wear and corrosion of the Ti-6Al-4V alloy [1]. This led to various endeavors to replace those alloying elements with safer ones, such as $\mathrm{Nb}$, Ta, and $\mathrm{Zr}$ [2]. Ti-13Nb-13Zr alloy is one of accomplishments from such endeavors, which is registered in the American Society for Testing and Materials (ASTM) standards for surgical implant applications [3].

Besides the cytotoxicity, implant materials have two requirements in terms of mechanical properties: high strength and low Young's modulus. The latter is the main interest, because it is much more difficult to control in comparison to the former. Young's modulus of human bone tissue is reported to be 10-30 GPa [4]. Although Ti and its alloys have been used for biomedical applications, their elastic moduli are still higher than that of bone tissue [5]. Excessive Young's moduli of traditional biomedical metals (e.g., Co-Cr-Mo, Grade $4 \mathrm{Ti}$, Ti-6Al-4V, and stainless steels) lead to a stress-shielding effect; they decrease an amount of stress applied to bone tissue near an implant, resulting in the weakening of human bone [6]. Compared with those materials, $\mathrm{Ti}-13 \mathrm{Nb}-13 \mathrm{Zr}$ is also beneficial to biomedical applications due to its moderately low Young's modulus. 
Mechanical properties of Ti alloys, including Young's modulus, are tailored by either plastic deformation or heat treatment. Both approaches change a microstructure of alloy towards the way beneficial to mechanical improvement. For example, Park et al. [7] employed a cross-rolling of water-quenched Ti-13Nb-13Zr to exploit a beneficial effect of dynamic globularization. Lee et al. [6] recently suggested a cold caliber rolling to confer high strength and low Young's modulus to Ti-13Nb-13Zr alloy. According to their study, the improvement stemmed from the effective grain refinement and formation of metastable martensitic phases. In contrast, relatively less attention has been paid to the other type of approach (i.e., heat treatment). Although Geetha et al. [8] and Majumdar et al. [9] carried out an extensive study of heat treatment, they focused on heat-treatment temperature and cooling rate rather than heat-treatment duration. The objective of this study is to clarify the kinetics of heat treatment in Ti-13Nb-13Zr alloy. Specifically, this study elucidates the relationship between the heat-treatment duration and mechanical compatibility (i.e., Young's modulus compensated with a mechanical strength) of Ti-13Nb-13Zr alloy.

\section{Materials and Methods}

The Ti-13Nb-13Zr alloy used in this study possessed a specific chemical composition of 13.8 mass $\% \mathrm{Nb}, 14.0$ mass $\% \mathrm{Zr}, 0.06$ mass\% $\mathrm{Fe}, 0.07$ mass\% O, 0.01 mass\% C, 0.007 mass\% N, and balance Ti. Samples were prepared in the dimension of $10 \times 10 \times 5 \mathrm{~mm}^{3}$. Geetha et al. [10] reported $\beta$-transus temperature $\left(T_{\beta}\right)$ of $1,008 \mathrm{~K}$ for Ti- $13 \mathrm{Nb}-13 \mathrm{Zr}$ alloy. Accordingly, Ti-13Nb-13Zr specimens were solution treated (ST) for $1073 \mathrm{~K}$ for $1 \mathrm{~h}$ and then soaked in a water bath to induce a rapid cooling [6,7]. Sections of these specimens were subsequently aged at $773 \mathrm{~K}$ for $10 \mathrm{~min}, 60 \mathrm{~min}$, $180 \mathrm{~min}$, and $360 \mathrm{~min}$, respectively, followed by air cooling. ASTM standard for the Ti-13Nb-13Zr alloy [3] refers to this aging process as a "capability aging" (CA). Hereafter, the aged specimens are denoted as CA10, CA60, CA180, and CA360 where the numbers indicate their CA duration in minutes.

The samples were water-abraded with $\# 400, \# 800, \# 1200, \# 2400$ emery paper, and then treated in different ways for characterization methods. No evidence for oxidation has been found after the mechanical polishing. Samples for X-ray diffraction (XRD, D8 Advance, Bruker, Billerica, MA, USA) analysis were mirror-polished using $3-\mu \mathrm{m}$ and $1-\mu \mathrm{m}$ ethanol-based diamond suspensions, respectively. Samples for scanning electron microscopy (SEM, SU8020, Hitachi, Tokyo, Japan) were prepared in the same manner followed by the final polishing with $0.05-\mu \mathrm{m}$ colloidal silica. Afterwards, SEM specimens were chemically etched in an aqueous solution containing $2 \%$ nitric acid and $2 \%$ fluoric acid. Samples for electron backscatter diffraction (EBSD, FEI QUANTA 3D FEG, Hillsboro, OR, USA) analysis were electropolished at $35 \mathrm{~V}$ in a solution of $5 \mathrm{~mL}$ perchloric acid (6\%) and $95 \mathrm{~mL}$ methanol. XRD measurement was performed in $2 \theta$ range from $30^{\circ}$ to $40^{\circ}$ at a scan speed of $0.75^{\circ} \cdot \mathrm{min}^{-1}$. EBSD data were analyzed using the TSL OIM software ver. 8 with a confidence index higher than 0.1 .

Young's modulus of heat-treated Ti-13Nb-13Zr alloys was determined in two ways. First, the alloys were machined into a cylindrical tensile specimen with gauge length in $10 \mathrm{~mm}$ and gauge diameter in $2.5 \mathrm{~mm}$. Tensile tests were repeated three times at a strain rate of $10^{-3} \mathrm{~s}^{-1}$ to secure a data reproducibility. Second, Young's modulus $(E)$ was measured using the velocities of an ultrasonic longitudinal wave $\left(V_{\mathrm{L}}\right)$ and transverse wave $\left(V_{\mathrm{T}}\right)$, expressed as follows [11]:

$$
E=\left[\rho V_{\mathrm{T}}^{2}\left(3 V_{\mathrm{L}}^{2}-4 V_{\mathrm{T}}^{2}\right)\right] /\left(V_{\mathrm{L}}^{2}-V_{\mathrm{T}}^{2}\right),
$$

where $\rho$ is the density of the investigated alloys.

\section{Results}

Figure 1 demonstrates microstructures of the investigated Ti-13Nb-13Zr alloys. ST alloy was investigated through the EBSD analysis as the SEM observation rarely confirmed its fine laths. The average width of its laths was determined to be $0.51 \pm 0.24 \mu \mathrm{m}$ (numbers including the standard deviation). The EBSD micrograph also confirmed a high frequency of submicron-sized twins inside 
relatively thick laths. These results are in good accordance with microstructural characteristics observed by transmission electron microscopy (TEM) [12]. The EBSD analysis yielded a volume fraction of $\beta$ phase of $0.6 \%$; however, this phase is highly likely to be absent in the ST alloy considering the thermomechanical processing route as well as an experimental error of measurement. This leaves the deduction that the ST alloy was fully composed of $\alpha$-variant phases (i.e., $\alpha, \alpha^{\prime}$, and $\alpha^{\prime \prime}$ ). The detailed phase constituents in the investigated Ti-13Nb-13Zr alloys are further discussed in Section 4.
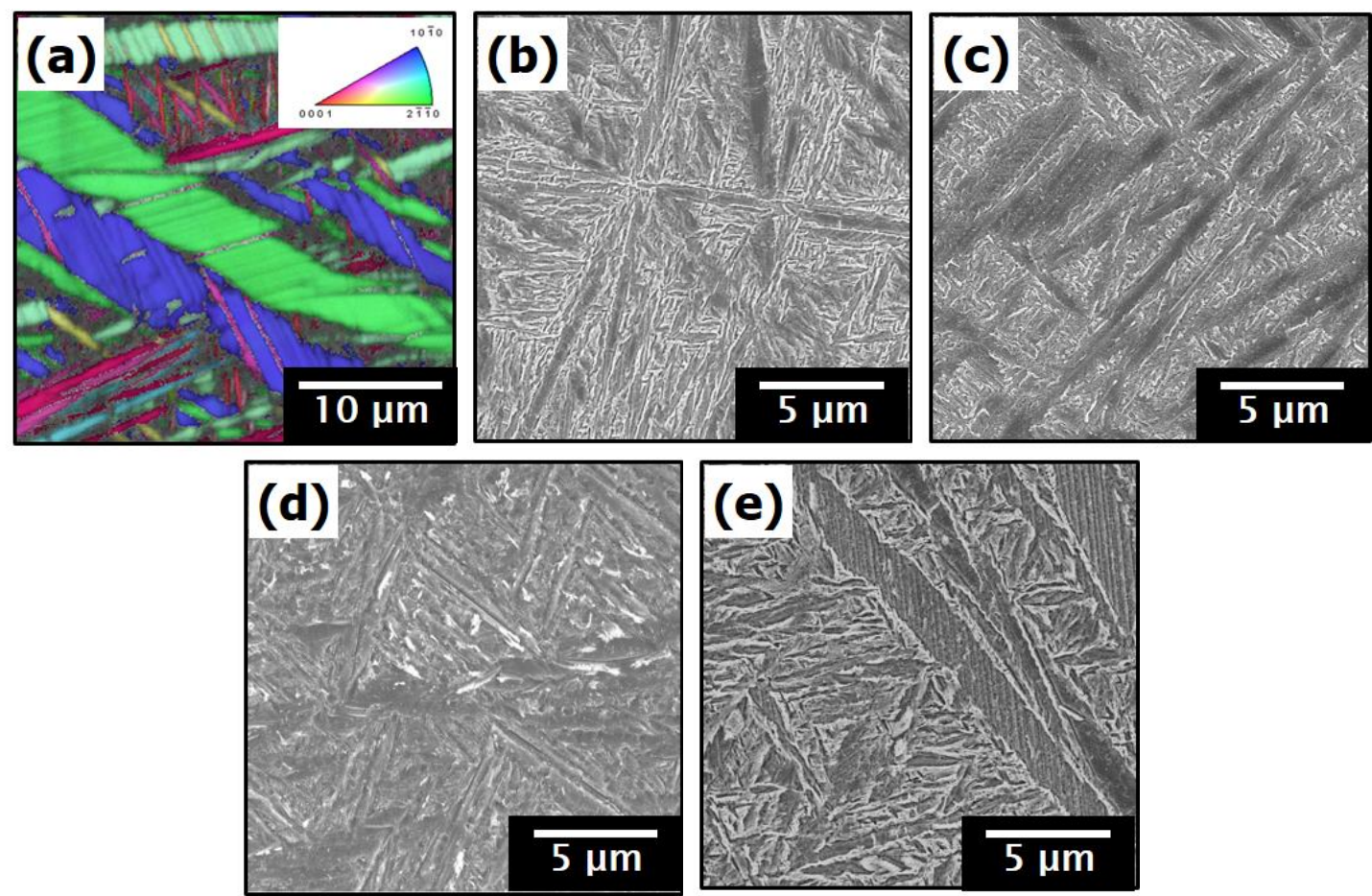

Figure 1. Microstructure of the investigated Ti-13Nb-13Zr alloys: (a) electron backscatter diffraction (EBSD) inverse pole figure map of ST alloy; (b) SEM micrograph of CA10, (c) CA60, (d) CA180, and (e) CA360 alloys.

Although CA samples presented the similar lath structure, the average width increased with an increase in CA duration: $1.64 \pm 0.5 \mu \mathrm{m}$ for CA10, $2.42 \pm 1.3 \mu \mathrm{m}$ for CA60, $2.73 \pm 1.1 \mu \mathrm{m}$ for CA180, and $3.01 \pm 1.5 \mu \mathrm{m}$ for CA360. This is not surprising because the longer CA process induced more active atomic diffusion and grain growth. The length of $\alpha$ laths extends more rapidly when compared with the thickness due to the diffusional ledge mechanism [13]. It is also noted that the CA360 alloy was fabricated on the basis of the ASTM standard [3]. This standardized procedure rapidly increased the lath width six-fold in comparison to that of the ST sample. The rate of grain growth became retarded as the alloy was aged for a longer duration. For example, the lath size increased by $0.78 \mu \mathrm{m}$ after CA treatment from $10 \mathrm{~min}$ to $60 \mathrm{~min}$, whereas it increased by $0.28 \mu \mathrm{m}$ from $180 \mathrm{~min}$ to $360 \mathrm{~min}$ despite 3.6-time longer duration of the heat treatment.

Figure 2 presents the XRD line profile of the investigated Ti- $13 \mathrm{Nb}-13 \mathrm{Zr}$ alloys. All samples show peaks at $2 \theta$ angle of $34.5^{\circ}, 38^{\circ}$, and $39.5^{\circ}$. These peaks correspond to the $\alpha$-variant phases, which are hardly distinguishable via XRD analysis due to a negligible difference in $2 \theta$ angles among the phases [6]. Nevertheless, the peaks for ST alloy are considered as the indication of $\alpha^{\prime}$ martensite, as discussed in Section 4. It is of particular note that CA180 and CA360 alloys exhibited a "shoulder" peak in the vicinity of the peak generated at $2 \theta$ angle of $38^{\circ}$, as marked by the arrows in Figure 2. Such a peak corresponds to (110) $\beta$ as confirmed in previous studies [14-16]. 


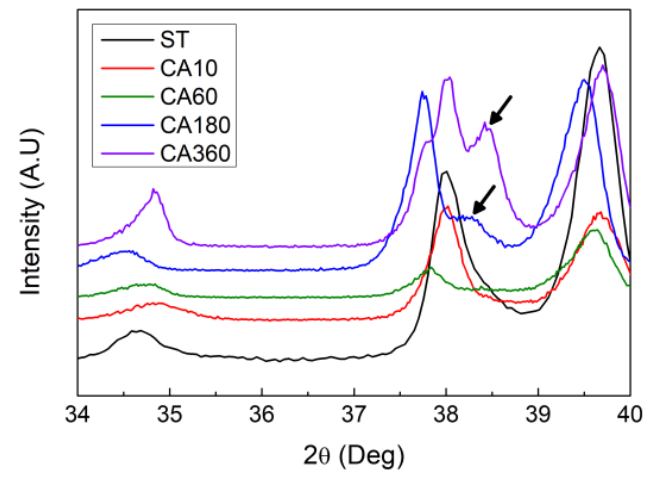

Figure 2. XRD line profiles of the investigated Ti-13Nb-13Zr alloys. The arrows indicate the "shoulder" peak corresponding to (110) $\beta$ phase.

Figure 3 shows a tensile deformation behavior of the investigated Ti-13Nb-13Zr alloys. Obviously, the flow curves of CA alloys are distinguished from that of the ST alloy in the aspects of an increase in yield strength (YS), ultimate tensile strength (UTS), and Young's modulus (E) as well as a decrease in elongation to failure (EL). Even the short-time $(10 \mathrm{~min}) \mathrm{CA}$ treatment considerably increased the mechanical strength in exchange for the EL reduction. Such trends (i.e., increasing strengths and decreasing EL) were intensified with an increase in CA duration. Meanwhile, ST alloy exhibited a remarkable hardening (i.e., UTS-YS) of $247 \mathrm{MPa}$, which was suppressed after applying the CA process, as shown in Figure $3 \mathrm{~b}$. The hardening decreased with increasing CA duration: $82 \mathrm{MPa}$ for CA10, $76 \mathrm{MPa}$ for CA60, $66 \mathrm{MPa}$ for CA180, and $54 \mathrm{MPa}$ for CA360.

(a)

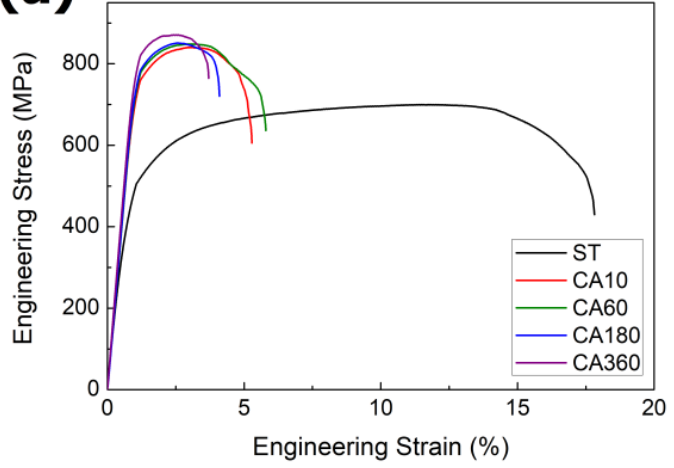

(b)

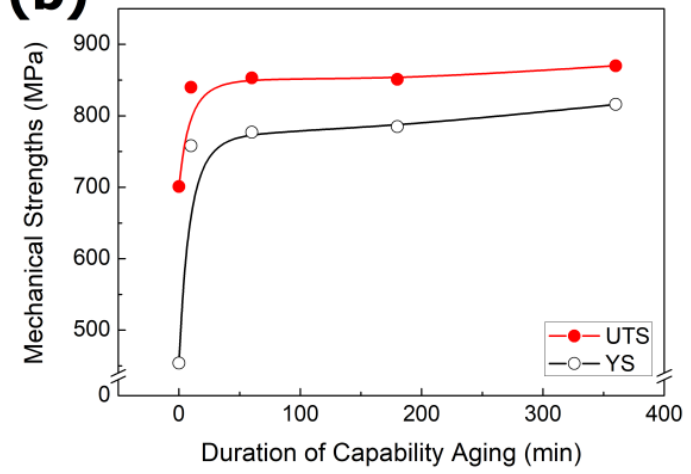

Figure 3. (a) Engineering stress-strain curves and (b) variation in mechanical strengths of the investigated Ti-13Nb-13Zr alloys as a function of capability aging (CA) duration. The data at the zero duration in Figure 3b indicate YS and UTS of ST alloy.

Figure 4 demonstrates increasing elastic moduli with increasing duration of the CA process, which is similar to the tendency for YS and UTS shown in Figure 3b. The trends were consistent in both measurements (i.e., tensile test and ultrasonic method). The data obtained from the slope of flow curve in the elastic regime were consistently higher than those measured via the ultrasonic method. Such a difference is acceptable in light of the intrinsic nature of the ultrasonic method, consistent with previous studies [11,17]. The mechanical properties of ST and CA360, fabricated on the basis of the ASTM standard, are in good accordance with those reported earlier [3,6,7], ensuring the data reliability of the present measurements. Table 1 summarizes the data of mechanical properties for the investigated materials. 


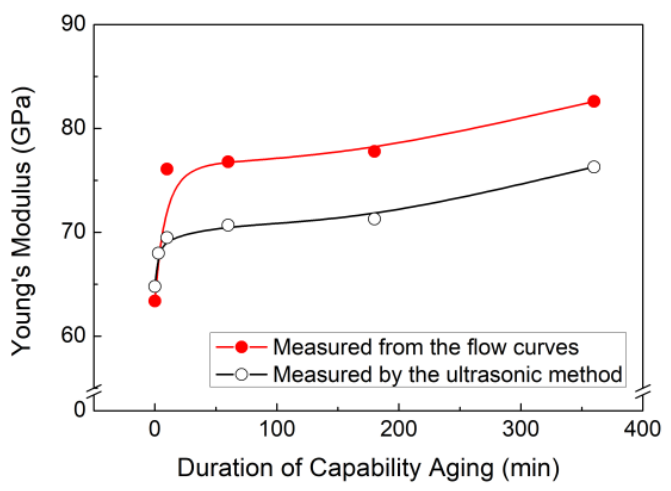

Figure 4. Variation in elastic moduli of the investigated $\mathrm{Ti}-13 \mathrm{Nb}-13 \mathrm{Zr}$ alloys as a function of CA duration. The data at the zero duration indicate Young's moduli of ST alloy.

Table 1. Mechanical properties of the investigated ST and CA alloys.

\begin{tabular}{cccccc}
\hline Sample & YS (MPa) & UTS (MPa) & E (GPa) & E (GPa) & EL (\%) \\
\hline ST & 454 & 701 & 63.4 & 64.8 & 17.8 \\
CA10 & 758 & 840 & 76.1 & 69.5 & 5.3 \\
CA60 & 777 & 853 & 76.8 & 70.7 & 5.8 \\
CA180 & 785 & 851 & 77.8 & 71.3 & 4.1 \\
CA360 & 816 & 870 & 82.6 & 76.3 & 3.7 \\
\hline
\end{tabular}

${ }^{*}$ Measured from the slope of flow curves in the elastic regime; ${ }^{\dagger}$ measured via the ultrasonic method.

\section{Discussion}

The Ti-13Nb-13Zr alloy can have five types of phases depending on a thermomechanical processing route: hexagonal close-packed (hcp) $\alpha$, body-centered cubic $\beta$, hcp $\omega$, hcp $\alpha^{\prime}$ martensite, and orthorhombic $\alpha^{\prime \prime}$ martensite. The $\alpha$ and $\beta$ phases are stable phases, while the others are metastable. Ti-13Nb-13Zr alloy has a significantly lower $T_{\beta}$ as compared with Ti-6Al-4V alloy [10]. Davidson et al. [18] suggested a martensite starting and finishing temperatures of $823 \mathrm{~K}$ and $758 \mathrm{~K}$, respectively. Accordingly, the water quenching from the temperature above $T_{\beta}$ induced the formation of full $\alpha^{\prime}$-martensitic structure in ST alloy. Kobayashi et al. [19] conducted a TEM study related to phase transformation in Ti-13Nb-13r alloy during a heat treatment at $873 \mathrm{~K}$. A rapid cooling from the $\beta$ domain causes a phase transformation into the full $\alpha^{\prime}$-martensitic phase, as consistent with the literature above. The subsequent heat treatment at $873 \mathrm{~K}$ leads to the formation of $\alpha^{\prime \prime}, \omega$, and $\beta$ phase in order with increasing duration from $5 \mathrm{~min}$ to $24 \mathrm{~h}$. The size and volume fraction of $\alpha$ precipitates are proportional to the heat-treatment temperature [20,21], of which the present condition $(773 \mathrm{~K})$ was lower than that adopted by the previous work ( $873 \mathrm{~K})$ [19]. This resulted in significantly small phases in the present CA alloys. In other words, $\alpha^{\prime \prime}$ and $\omega$ phases, as well as $\beta$ in the short-time aged samples, were too small to be observed through SEM and EBSD methods. Meanwhile, $\alpha$ phase precipitated at the phase interfaces and twin boundaries of the initial $\alpha^{\prime}$ martensite, resulting in the decomposition into stable $\alpha$ and $\beta$ phases [22]. Their conclusions are consistent with the present results of (i) the full $\alpha^{\prime}$-martensitic structure of ST alloy, (ii) the presence of $\beta$ peaks for CA180 and CA360 samples, and (iii) the decomposition of $\alpha^{\prime}$ martensite into $\alpha$ and $\beta$ phases during the CA process.

Young's modulus is an intrinsic material property determined by the atomic bonding forces. Such forces are dependent not only on a crystal structure but also on the distance between atoms, and thus affected by alloying elements, heat treatment, and plastic deformation [23,24]. In the present study, the primary factor for Young's modulus is the presence of various phases. The lowest Young's modulus of ST alloy arose from the full $\alpha^{\prime}$-martensitic structure [9]. The subsequent CA process induced the formation of hard $\alpha$ precipitates possessing higher strength and Young's modulus [25]. Increasing fraction of this phase with increasing CA duration gave rise to an increment in strength and Young's 
modulus of the investigated Ti-13Nb-13Zr alloys, as presented in Figures 3 and 4 . The reduction of hardening with increasing CA duration is also understood in terms of increasing the fraction of $\alpha$ precipitates.

Recalling Figure 4, Young's modulus rapidly increased in the early stage of CA process, followed by the retarded increment in the late stage. An additional sample was fabricated by applying a 3-min CA process to confirm this tendency. It exhibited Young's modulus of $68 \mathrm{GPa}$ based on the ultrasonic method, which was close to that of CA10 rather than ST alloy. These results imply that the $\alpha^{\prime}$ decomposition into $(\alpha+\beta)$ structure occurred as soon as the alloy was subjected to the CA process.

The results obtained in this work have proven the proportional relationship between mechanical strength and Young's modulus. Such a relation is unfavorable for a biomedical application that requires high strength and a low Young's modulus. This is further supported in terms of mechanical compatibility defined as the ratio of YS to Young's modulus. Figure 5 presents the mechanical compatibilities of the investigated Ti-13Nb-13Zr alloys as well as reported values $[6,7,9,12,18,26,27]$. Neither the ST nor CA process gave rise to a meaningful improvement in mechanical compatibility, suggestive of an intrinsic limit of static heat treatment. It is thus required to find an alternative thermomechanical process inhibiting the precipitation of hard $\alpha$ phase, such as the combination of martensitic transformation and grain refinement suggested recently [6].

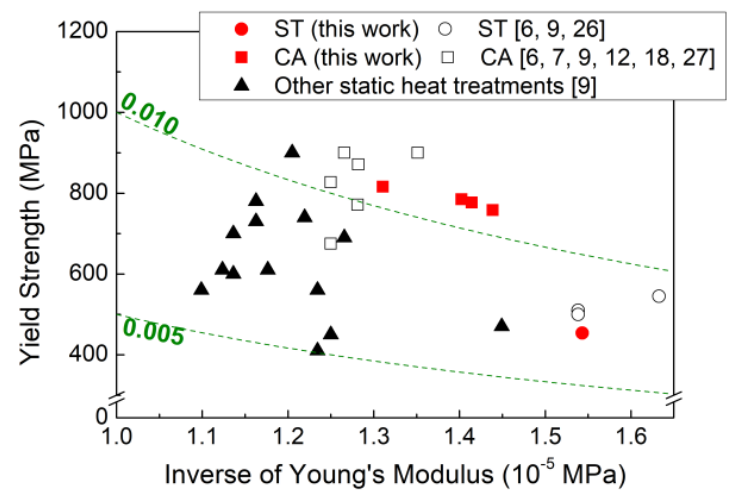

Figure 5. Mechanical compatibilities of the investigated and reported Ti-13Nb-13Zr alloys [6,7,9,12,18,26,27]. The green lines indicate the corresponding value of mechanical compatibility (i.e., YS/E).

\section{Conclusions}

This study has clarified the kinetics of heat treatment (i.e., CA treatment suggested by the ASTM standard) in Ti-13Nb-13Zr alloy in terms of microstructural evolution and changes in mechanical compatibility. The initial ST alloy was composed of the full $\alpha^{\prime}$-martensitic structure, which was decomposed into stable $\alpha$ and $\beta$ phases during the subsequent CA process. The precipitation of the hard $\alpha$ phase with increasing CA duration resulted in the simultaneous increase in mechanical strength and Young's modulus. Such a tendency was unfavorable for biomedical application that demands high strength and low Young's modulus. Indeed, the CA process rarely enhanced the mechanical compatibility of Ti-13Nb-13Zr alloys regardless of the treatment duration. It is thus required to employ an alternative processing route, rather than ST or CA treatments, that enables mechanical strengthening without the precipitation of hard $\alpha$ phase.

Author Contributions: Conceptualization, T.L, M.L., and C.H.P.; methodology, T.L. and C.H.P.; investigation, M.L. and I.-S.K.; resources, T.L., C.H.P., Y.H.M., and H.S.Y.; writing—original draft preparation, M.L. and T.L.; writing -review and editing, M.L. and T.L.; supervision, T.L.; project administration, T.L. and H.S.Y.; funding acquisition, T.L. All authors have read and agreed to the published version of the manuscript.

Funding: This work was supported by the National Research Foundation of Korea (NRF) grant funded by the Korean government (MSIT) (No. 2018R1C1B6002068).

Conflicts of Interest: The authors declare no conflict of interest. 


\section{References}

1. Michalska, J.; Sowa, M.; Piotrowska, M.; Widziołek, M.; Tylko, G.; Dercz, G.; Socha, R.P.; Osyczka, A.M.; Simka, W. Incorporation of Ca ions into anodic oxide coatings on the Ti-13Nb-13Zr alloy by plasma electrolytic oxidation. Mater. Sci. Eng. C 2019, 104, 109957. [CrossRef] [PubMed]

2. Kolli, R.; Devaraj, A. A Review of Metastable Beta Titanium Alloys. Metals 2018, 8, 506. [CrossRef]

3. ASTM F1713-08(2013). Standard Specification for Wrought Titanium-13Niobium-13Zirconium Alloy for Surgical Implant Applications (UNS R58130); ASTM International: West Conshohocken, PA, USA, 2013.

4. Niinomi, M. Mechanical biocompatibilities of titanium alloys for biomedical applications. J. Mech. Behav. Biomed. Mater. 2008, 1, 30-42. [CrossRef] [PubMed]

5. Niinomi, M.; Kuroda, D.; Fukunaga, K.I.; Morinaga, M.; Kato, Y.; Yashiro, T.; Suzuki, A. Corrosion wear fracture of new $\beta$ type biomedical titanium alloys. Mater. Sci. Eng. A 1999, 263, 193-199. [CrossRef]

6. Lee, T.; Lee, S.; Kim, I.-S.; Moon, Y.H.; Kim, H.S.; Park, C.H. Breaking the limit of Young's modulus in low-cost Ti-Nb-Zr alloy for biomedical implant applications. J. Alloys Compd. 2020, 828, 154401. [CrossRef]

7. Park, C.H.; Park, J.-W.W.; Yeom, J.-T.T.; Chun, Y.S.; Lee, C.S. Enhanced mechanical compatibility of submicrocrystalline Ti-13Nb-13Zr alloy. Mater. Sci. Eng. A 2010, 527, 4914-4919. [CrossRef]

8. Geetha, M.; Singh, A.K.; Muraleedharan, K.; Gogia, A.K.; Asokamani, R. Effect of thermomechanical processing on microstructure of a Ti-13Nb-13Zr alloy. J. Alloys Compd. 2001, 329, 264-271. [CrossRef]

9. Majumdar, P.; Singh, S.B.; Chakraborty, M. The role of heat treatment on microstructure and mechanical properties of Ti-13Zr-13Nb alloy for biomedical load bearing applications. J. Mech. Behav. Biomed. Mater. 2011, 4, 1132-1144. [CrossRef]

10. Geetha, M.; Kamachi Mudali, U.; Gogia, A.K.; Asokamani, R.; Raj, B. Influence of microstructure and alloying elements on corrosion behavior of Ti-13Nb-13Zr alloy. Corros. Sci. 2004, 46, 877-892. [CrossRef]

11. Majumdar, P.; Singh, S.B.; Chakraborty, M. Elastic modulus of biomedical titanium alloys by nano-indentation and ultrasonic techniques-A comparative study. Mater. Sci. Eng. A 2008, 489, 419-425. [CrossRef]

12. Lee, T.; Heo, Y.-U.U.; Lee, C.S. Microstructure tailoring to enhance strength and ductility in Ti-13Nb-13Zr for biomedical applications. Scr. Mater. 2013, 69, 785-788. [CrossRef]

13. Wang, J.N.; Yang, J.; Xia, Q.; Wang, Y. On the grain size refinement of TiAl alloys by cyclic heat treatment. Mater. Sci. Eng. A 2002, 329-331, 118-123. [CrossRef]

14. Saji, V.S.; Choe, H.C. Electrochemical corrosion behaviour of nanotubular Ti-13Nb-13Zr alloy in Ringer's solution. Corros. Sci. 2009, 51, 1658-1663. [CrossRef]

15. Zhou, L.; Yuan, T.; Li, R.; Tang, J.; Wang, M.; Li, L.; Chen, C. Microstructure and mechanical performance tailoring of Ti-13Nb-13Zr alloy fabricated by selective laser melting after post heat treatment. J. Alloys Compd. 2019, 775, 1164-1176. [CrossRef]

16. Lee, T.; Park, K.-T.T.; Lee, D.J.; Jeong, J.; Oh, S.H.; Kim, H.S.; Park, C.H.; Lee, C.S. Microstructural evolution and strain-hardening behavior of multi-pass caliber-rolled Ti-13Nb-13Zr. Mater. Sci. Eng. A 2015, 648, 359-366. [CrossRef]

17. Kumar, P.; Mahobia, G.S.; Singh, V.; Chattopadhyay, K. Lowering of elastic modulus in the near-beta Ti-13Nb-13Zr alloy through heat treatment. Mater. Sci. Technol. 2020, 36, 717-725. [CrossRef]

18. Davidson, J.A.; Mishra, A.K.; Kovacs, P.; Poggie, R.A. New surface-hardened, low-modulus, corrosion-resistant Ti13Nb13Zr alloy for total hip arthroplasty. Biomed. Mater. Eng. 1994, 4, 231-243.

19. Kobayashi, S.; Nakagawa, S.; Nakai, K.; Ohmori, Y. Phase Decomposition in a Ti-13Nb-13Zr Alloy during Aging at $600{ }^{\circ} \mathrm{C}$. Mater. Trans. 2002, 43, 2956-2963. [CrossRef]

20. Moffat, D.L.; Larbalestier, D.C. The competition between martensite and omega in quenched Ti-Nb alloys. Metall. Mater. Trans. A 1988, 19, 1677-1686. [CrossRef]

21. Hussein, M.A.; Azeem, M.; Kumar, A.M.; Al-Aqeeli, N.; Ankah, N.K.; Sorour, A.A. Influence of Thermal Treatment on the Microstructure, Mechanical Properties, and Corrosion Resistance of Newly Developed Ti20Nb13Zr Biomedical Alloy in a Simulated Body Environment. J. Mater. Eng. Perform. 2019, 28, 1337-1349. [CrossRef]

22. Gil Mur, F.X.X.; Rodríguez, D.; Planell, J.A. Influence of tempering temperature and time on the $\alpha^{\prime}-\mathrm{Ti}-6 \mathrm{Al}-4 \mathrm{~V}$ martensite. J. Alloys Compd. 1996, 234, 287-289. [CrossRef] 
23. Hao, Y.; Yang, R.; Niinomi, M.; Kuroda, D.; Zhou, Y.; Fukunaga, K.; Suzuki, A. Young's modulus and mechanical properties of Ti-29Nb-13Ta-4.6Zr in relation to $\alpha$ " martensite. Metall. Mater. Trans. A 2002, 33, 3137-3144. [CrossRef]

24. Zhou, Y.L.; Niinomi, M.; Akahori, T. Effects of Ta content on Young's modulus and tensile properties of binary Ti-Ta alloys for biomedical applications. Mater. Sci. Eng. A 2004, 371, 283-290. [CrossRef]

25. Matsumoto, H.; Watanabe, S.; Hanada, S. Microstructures and mechanical properties of metastable [beta] TiNbSn alloys cold rolled and heat treated. J. Alloys Compd. 2007, 439, 146-155. [CrossRef]

26. Baptista, C.A.R.P.; Schneider, S.G.; Taddei, E.B.; da Silva, H.M. Fatigue behavior of arc melted Ti-13Nb-13Zr alloy. Int. J. Fatigue 2004, 26, 967-973. [CrossRef]

27. Zhentao, Y.; Lian, Z. Influence of martensitic transformation on mechanical compatibility of biomedical $\beta$ type titanium alloy TLM. Mater. Sci. Eng. A 2006, 438-440, 391-394. [CrossRef]

C 2020 by the authors. Licensee MDPI, Basel, Switzerland. This article is an open access article distributed under the terms and conditions of the Creative Commons Attribution (CC BY) license (http://creativecommons.org/licenses/by/4.0/). 